\title{
Microgenesis, Method and Object: A Study of Collaborative Activity in a Spanish as a Foreign Language Classroom
}

\author{
ADELA GÁNEM GUTIÉRREZ \\ University of Essex
}

\begin{abstract}
This paper draws on the Vygotskian methodological construct of microgenesis to study collaborative activity in an intermediate Spanish as a foreign language classroom. In this study, the construct of microgenesis is drawn upon to refer to both, the methodological tool to investigate language learning instances as observed in short periods of time (i.e. minutes), and also to refer to those observed language learning instances as the object of study. The Sociocultural approach to Second Language Learning (SLL) (Lantolf and Appel 1994; Donato 2000; Lantolf 2000; Lantolf and Thorne 2006) underpinning this investigation sees interaction as the enabling process that becomes essential for the individual to achieve learning and development. I refer to learning as the process through which participants are able to change, transform (i.e. develop) their use and/or understanding (see Wells 1999: 111) of the target language. Pairs/trios of students were audio-recorded while collaborating to complete three language tasks in the classroom during an academic semester in a UK university. Microgenetic analysis of the data (transcribed protocols) allowed us to gain further understanding of collaborative activity and of the importance of language as a mediational tool to co-construct meaning and learning opportunities. The results show that although each instance of microgenesis is unique, there are certain characteristics and patterns shared by the various instances identified in the data set. The investigation also highlights the importance of studying discourse markers to help us identify the learners' level of regulation. Finally, we focus on a specific aspect of microgenesis that appears to be crucial for driving the learner's second language (L2) forward, and which following van Lier (2000: 252), I refer to as microgenesis affordance.
\end{abstract}

\section{INTRODUCTION}

the search for method becomes one of the most important problems of the entire enterprise of understanding the uniquely human forms of psychological activity. In this case, the method is simultaneously prerequisite and product, the tool and the result of the study.

(Vygotsky 1978: 65, italics in the original)

This study aims to contribute to the growing body of research (Donato 1988, 1994; Ohta 1995, 2001; Antón and DiCamilla 1998; Swain and Lapkin 1998) looking into collaborative activity from a sociocultural approach 
to second language learning (SLL). The paper reports on an investigation of microgenesis (i.e. the moment-to-moment co-construction of language and language learning) in a Spanish language classroom (Intermediate level) as learners worked in dyads/triads across three different problem-solving tasks. The foundations for the study lie in what is considered one of Vygotsky's most important contributions to the study of mind (Lantolf and Thorne 2006: 225), his developmental or genetic analysis as a means to understand certain aspects of mental functioning, 'analysis that returns to the source and reconstructs all the points in the development of a given structure' (Vygotsky 1978: 65). Vygotsky conceived the mind as a system consisting of both natural/biological functions and, importantly, cultural-higher-mental functions, such as voluntary attention, problem-solving capacity, planning, learning, and intentional memory. His primary interest lay in the study of these higher mental capacities and he proposed four genetic domains to do so. The phylogenetic domain relates to how the human mind evolved differently from other life forms, by means of culturally mediated tools. The sociocultural domain concerns mediation and the different kinds of mediational tools adopted and valued by society. The ontogenetic domain studies the appropriation of these mediational tools and how they are integrated into cognitive activity during the processes of an individual's development. Finally, the microgenetic domain focuses on the overt, in flight, instance of learning as it happens during interpsychological activity (Robbins 2001) 'over a relatively short span of time (for example... learning a word, sound, or grammatical feature of a language)' (Lantolf 2000: 3).

Microgenesis, or the study of the origin and history of a particular event, is described by Wertsch as 'a very short-term longitudinal study' (Wertsch 1985: 55). Microgenesis, refers simultaneously to both the method and the object of study. Microgenetic or historical analysis allows us to investigate and understand a particular event (learning as an object of study), or as Mitchell and Myles (2004: 198) describe it 'a local, contextualized learning process... [that] can sometimes be traced visibly in the course of talk between expert and novice.' It is precisely this conceptual duality that makes microgenetic analysis a fruitful method to investigate learning (microgenesis) as it unfolds during interaction.

Researchers like Donato (1994), Swain (1997), Swain and Lapkin (2001), and Roschelle and Teasley (1995) have identified collaborative dialogue that emerges from learners' interactions when engaged in problem-solving activity as the kind of interaction that can potentially lead to language development. In Swain's words, collaborative dialogue 'is where language use and language learning can co-occur. It is language use mediating language learning. It is cognitive activity and social activity' (Swain 2000: 97). In this paper I propose that microgenesis (method and object of study) as applied specifically to the field of SLL embodies both the identification of collaborative dialogue and its microgenetic investigation as a learning process that can be observed while learners engage in goal-directed communication. I refer 
to development as mediated problem-solving activity where participants are able to overcome a specific language difficulty while carrying out a classroom-based language task, and therefore, cannot claim that the learners will be able to use the language in question in the long term without requiring 'conscious attention [and/or] external assistance' (Lantolf and Thorne 2006: 221). For ontogenetic studies where longer term development has been documented see Belz and Kinginger (2003), Belz and Vyatkina (2005), Kinginger and Belz (2005), and Ohta (2001), for example.

Analytically, the exploration of how learners make use of language as a mediational tool during collaborative activity is of paramount importance (Frawley 1992; DiCamilla and Anton 1997; Roebuck 2000; Swain and Lapkin 2000). Furthermore, I propose that although each instance of microgenesis (see method below) is unique since it is co-created by individuals with their own histories and goals, there are certain characteristics and patterns that appear to be similar throughout the various instances of microgenesis identified in the data. Although each developmental instance is unique and 'contingent upon individual learner experiences' (Belz and Vyatkina 2005: 42 ), this study unravels similar patterns emerging from various microgenesis instances, which show the workings, and interrelation between what the individual brings to the interaction and what gets constructed in collaboration. ${ }^{1}$ An important issue in our discussion is the analysis of discourse markers, which together with Aljaafreh and Lantolf's (1994) regulatory scale, help us gain further insights into the participants' level of regulation.

The following section provides a brief overview of Sociocultural Theory and some key concepts that underpinned this investigation. Subsequently, I describe the method and context in which the study was carried out. Finally, the analysis and results sections provide an in-depth examination of microgenesis as a developmental process, before focusing on a specific aspect that appears to be crucial for driving the learner's L2 forward, and which I refer to as microgenesis affordance.

\section{SOCIOCULTURAL THEORY}

Sociocultural Theory is a theory of mental development rooted in the work of the Russian psychologist Lev S. Vygotsky (1896-1934). Three interwoven major ideas form the basis of Vygotsky's work: (1) an emphasis on developmental or genetic analysis as a means to understand certain aspects of mental functioning; (2) the claim that individual mental functioning has social origins; and (3) an emphasis on the mediated nature of human action (Wertsch 1991: 25). The implications of these ideas as applied to our understanding of knowledge ${ }^{2}$ and learning (i.e. knowledge building) are profound. Knowledge, hereby understood not as an object to be 'possessed' or a commodity to be accumulated by the individual (see Sfard 1998: 5), but as an understanding which is 'recreated, modified, and extended in and through collaborative knowledge building ${ }^{3}$ and individual understanding' 
(Wells 1999: 89). For Vygotsky, knowledge is not created in the individual mind, it is essentially created in the social realm, through interaction. The importance of knowledge and how it is socially co-constructed is stressed by Wells (1992) by means of three principles. First of all, knowledge is interpsychologically created by knowledgeable individuals, therefore it is not conceived as a pre-existent product waiting to be exchanged; secondly, this knowledge co-construction is both social and cultural; and finally, its construction is always mediated by cultural processes and tools, either physical or psychological (Wells 1992: 286-287; see also Mercer and Scrimshaw 1993). The process through which activity, that is originally mediated/regulated by tools and other people, is transferred from the social to the individual plane is referred to as internalization. This process is achieved by appropriating the means of regulation and manipulating them voluntarily (Lantolf 2000).

Learning, or the development of increasingly effective ways of dealing with the world and its meanings' (van Lier 2000: 246) is seen in Sociocultural Theory as a mediated process that originates in societal activity where the issues of instruction, agency, and situatedness need to be considered. The role of instruction is fundamental to this approach. Instruction is essentially a collaborative act where zones of proximal development (ZPD) - in Vygotsky's words, 'the discrepancy between a child's actual mental age and the level he reaches in solving problems with assistance' (Vygotsky 1986: 187)-are created by the participants, agents with their own social perspectives and histories, goals, attitudes, etc. Ohta (1995, 2001) has adapted the construct for the L2 learner as the distance between the actual developmental level as determined by individual linguistic production, and the level of potential development as determined through language produced collaboratively with a teacher or peer' (Ohta 2001: 9). The situated quality of learning means that circumstance is a pervasive aspect that has to be carefully considered since 'learning unfolds in different ways under different circumstances' (Donato 2000: 47).

Finally, Activity Theory (Leontiev 1978) provides an analytic frameworkrooted in Sociocultural Theory-for the systematic investigation of collaborative activity in the classroom. According to Wertsch (1985), Activity Theory raises the fundamental question of what the individual or group is doing in a particular setting. In order to find this out, it is necessary to investigate what the motivation behind the activity is. For analytical purposes activity can be categorised into three different levels: activity (why something takes place, motive oriented), action (what is being done, goal oriented), and operation (the actual doing, means oriented) (Lantolf and Thorne 2006: 217).

\section{METHOD AND CONTEXT OF THE STUDY}

The study was conducted in a Spanish as a foreign language classroom for undergraduate students throughout an academic semester where the author was also the class teacher. The participants were eleven females and 
seven males in their late teens/early twenties. Their level of Spanish was intermediate, which corresponds to a grade $\mathrm{C}$ in ' $\mathrm{A}$ ' level Spanish, the national qualification within the British Education context taken at the end of secondary schooling. This classroom-based study focused upon the following grammatical structures which were the content of the course programme established by the language department at the university: personal pronouns to include subject, direct and indirect object; prepositional and reflexive pronouns; infinitive verbs; radical changing verbs; and 'ser' vs. 'estar' (the two Spanish verbs for 'to be'). None of these structures were expected to be completely new for the students although, as a pre-test showed, they did indeed have problems with their use.

In line with a microgenetic method of data analysis and in order to facilitate the study of activity as it unfolds throughout task completion, the main instrument for data collection was the task. ${ }^{4}$ Learners were audiorecorded while performing language tasks in pairs/groups. The recorded data ( $5 \mathrm{hr} 20 \mathrm{~min}$ of learners' interaction) were transcribed, based on procedures from Psathas (1995) and Ohta (2001), to produce protocols for data analysis. The three tasks, described below, were implemented in two modes: computer-based and paper-based. The purpose for comparing the two modes of implementation was to facilitate the study of the computer pervasiveness in activity. This issue, however, is beyond the scope of the present article, for the full study and specific results in relation to the computer the reader is referred to Gánem-Gutiérrez 2004).

Half of the dyads accomplished a Computer-Assisted Language Learning (CALL) task and half a paper task. In the interest of preserving the normal conditions of this classroom-based study, students chose their partners as this was the normal practice throughout the semester. However, they were asked to work alternately between the two modes throughout the three tasks. In other words, participants who worked on CALL mode in task 1 were then asked to work on paper mode in task 2 and so on. The study corpus therefore comprised twelve protocols, which were managed and analysed with the assistance of two software packages: $N 5^{5}$ and Microsoft ${ }^{\circledR}$ Excel. Students also took a grammar test at the beginning and at the end of the study (pre- and post-tests respectively) in order to evaluate changes in their use of the grammatical structures mentioned above (for a report of these results refer to Gánem-Gutiérrez 2004).

\section{The tasks}

Three problem-solving tasks were specifically designed as the main data collection instrument to record the processes of collaboration undergone by participants while accomplishing them either at the computer (CALL tasks) ${ }^{6}$ or in a paper version (paper tasks). The two main methodological purposes of the tasks as instruments for data collection were (1) to provide the participants with an opportunity to engage in interpsychological activity 
by collaborating to complete them; (2) to promote the generation of L2 since this might lead to language development-for example through focusing on form; by 'pushing' learners to get involved in more mental efforts and so, process language at a deeper level; by moving from semantic to strategic levels in order to achieve accurate production (Swain 1995).

The completion of each of the three problem-solving tasks (see brief descriptions below) represented an overall goal. However, to achieve that goal, students also needed to engage in discrete, grammar oriented exercises or micro-tasks implemented as gap-filling, translation, jumbled sentences, and/or caption writing. These embedded micro-tasks were designed to prioritise work on specific language issues, that is personal pronouns (tasks 1 and 2), infinitive and radical changing verbs (task 2), and 'ser' vs. 'estar' (task 3). Inter-mental activity was expected to take place in relation to communication for meaning (throughout each task as a whole), metalinguistic talk (when tackling the grammar specific exercises embedded in each task), and metacognitive activity (when planning and organising how to tackle the tasks). The latter is considered to be particularly important to stimulate individuals, provide them with an infrastructure supporting development, take and manage control of their activity and learning, and guide them through the tasks (Hoven 1999; Swain 2000; Ohta 2001).

Feedback and help from the computer were provided in various degrees and three different ways: clues, hints, and a correction button. Learners working on the paper tasks received feedback and help from the teacherresearcher who was always available to everyone.

\section{Task 1: Professionals Today}

This task consisted of three parts: (1) a discussion about the world of work, implemented through a hierarchical exercise where participants had to organise concepts such as 'power' and 'money' according to what they considered more or less important in the world of work; (2) an interview reconstruction of a Spanish professional talking about his views of the world of work (a range of personal pronouns were needed to successfully complete 1 and 2); and (3) creation of a document to express participants' own views about the topic, but in the context of the UK.

\section{Task 2: Gifted Daughters}

Task two was a problem-solving task where participants were given clues that would help them solve a problem posited: to find out which language and which musical instrument belonged to which of five sisters. To solve the problem the dyads had to collect five clues (e.g. 'la hermana que toca el piano no habla alemán' the sister that plays the piano doesn't speak German), which were provided to them, one at a time, on the computer screen-or on 
a piece of paper handed in by the teacher-after completing micro-tasks based on grammar (e.g. focusing on personal pronouns, and infinitive and radical changing verbs).

\section{Task 3: Mexico City}

Finally, the third task was an adaptation of 'dictogloss' (Kowal and Swain 1997: 295 and Swain and Lapkin 2001: 101) which is described as a 'procedure' which encourages learners to reflect on their L2. 'In this procedure, a short, dense text is read to the learners at normal speed; while it is being read, students jot down familiar words and phrases; the learners work together in small groups to reconstruct the text from their shared resources...' (Kowal and Swain 1997: 295).

In the CALL version of dictogloss, participants read a text provided on the computer screen instead of listening to it, they then worked on its reconstruction on the computer (several examples of the verbs 'ser' and 'estar' were used). The paper version of this task consisted of three pages: one with the instructions, another one with the text, and a third one with the title of the text and blanks for learners to reconstruct it; as in the CALL version, punctuation marks were provided.

To summarise, the three tasks designed for collection of data in this study provided the students with a twofold and explicit general objective. On the one hand, students had the specific aim of completing the problem solving phase of the tasks, and on the other hand, they were able to reflect on language by working on the grammatical structures that were part of the exercises embedded in the tasks.

\section{ANALYSIS AND RESULTS}

\section{Microgenesis Instances (MGIs)}

A fundamental premise within Vygotskian theory of cognitive development is that development first appears in the interpsychological plane, that is through social interaction, and it is then internalised by the individual in the intrapsychological plane (Ohta 2000: 54). Furthermore, the origins and processes of development (microgenesis) are sometimes visible as they unfold during interaction.

In order to study collaborative activity and to assess its relevance for SLL, all language related episodes (LREs) were identified throughout the data. An LRE is defined as 'any part of a dialogue where the students talk about the language they are producing, question their language use, or correct themselves or others' (Swain and Lapkin 1995). Subsequently, the full set of LREs in the data was further analysed and studied in order to identify those LREs where there were overt signs (e.g. correcting an erroneous form) that some language improvement had taken place, these are what I am referring 
to as instances of microgenesis. Table 1 shows the number of microgenesis instances (MGIs) identified in each protocol.

As Table 1 shows, there are few microgenesis instances in relation to the total number of LREs per task, but with a much higher ratio in tasks 2 and 3 . Merging the figures of the four protocols per task, task 1 contained the lowest percentage of MGIs of the three, with only 7 per cent whereas tasks 2 and 3 mirror each other with 14 per cent.

Deriving from the construct of language related episode (LRE) devised to study language related activity during collaboration (Swain 1998; Swain and Lapkin 1995, 2000), MGIs are another analytical construct that helps us investigate language learning activity and some of the processes underlying it while learners engage in collaboration as shown in the instance below. In the example, learners are engaged in an interview reconstruction through gap filling, and specifically focusing on the reflexive pronoun 'se':

(CT1) microgenesis instance (MGI2)

(See the Appendix for transcription conventions)

98 M 'avanzar'

'go on' ((reading while pressing button on screen))

99 E 'ahora a la entrevista'

'now to the interview'

100 M uhum

101 E 'buenos dias buenos dias en su opinión en qué'

'good morning good morning in your opinion what is'

102 M 'hoy en' día (.) 'hoy en' día

'now a'days (.) 'nowadays'

$\Longrightarrow 103 \mathrm{E}$ en qué lo? Basa

what is it ((wrong pronoun)) based on?

ב $104 \mathrm{M} \quad$ 'en su opinión en qué' (.) para quién (.) en general o

'in your opinion what is' (.) for whom (.) in general or

$\Longrightarrow 105$ E 'en qué en qué' se 'basa'?

'what is what is' se ((correct pronoun)) 'based on'

$\Rightarrow 106 \quad \mathrm{M} \quad \mathrm{si}$

yes

107 E si?

yes?

$108 \mathrm{M}$ es posible no estoy seguro segura ((laughter))

it's possible I'm not sure

109 E si ((laughter))

yes 
Table 1: Language related activity: number of language related and microgenesis instances

\begin{tabular}{|c|c|c|c|c|c|c|c|c|c|c|c|c|c|c|c|}
\hline & \multicolumn{5}{|c|}{ Task 1} & \multicolumn{5}{|c|}{ Task 2} & \multicolumn{5}{|c|}{ Task 3} \\
\hline & CTl & $2 \mathrm{CTl}$ & PT1 & $2 \mathrm{PTl}$ & Total task 1 & CT2 & $2 \mathrm{CT} 2$ & PT2 & 2PT2 & Total task 2 & CT3 & $2 \mathrm{CT} 3$ & PT3 & $2 \mathrm{PT} 3$ & Total task 3 \\
\hline Total no. of LREs & 28 & 29 & 26 & 38 & 121 & 14 & 12 & 12 & 12 & 50 & 15 & 2 & 19 & 14 & 50 \\
\hline Total no. of MGIs & 3 & 0 & 3 & 2 & 8 & 2 & 3 & 2 & 0 & 7 & 0 & 0 & 7 & 0 & 7 \\
\hline
\end{tabular}

Note: $\mathrm{CTl}=$ protocol 1 computer-task $1 ; 2 \mathrm{CTl}=$ protocol 2 computer-task $1 ; \mathrm{PTl}=$ protocol 1 paper-task 1 , etc. 
This instance shows how the dyad creates a collective opportunity which is then cognitively seized by Ellen (all names are pseudonyms) in turn 105 . From turn 98 onwards, they both use reading aloud as a cognitive tool for regulation to try and fill in a gap with a personal pronoun (se). In turn 103 Ellen advances an option-lo-which is not correct, but which nevertheless brings Mina to focus onto personal pronouns (she had just been working on a noun 'día' for a different gap), see turn 104. This turn is at the core of the MGI when Mina engages with this particular problem-solving endeavour and reads aloud part of the sentence as a focus tool and then, after a pause, produces some kind of metalinguistic private speech. ${ }^{7}$

Although we do not have further data, for example a retrospective interview with the participants that would throw more light on Mina's processes and thoughts when uttering speech turn 104 nor an insight into what Ellen might have thought made her correct the pronouns, we do know from the data that Ellen's L2 is modified immediately after Mina's self-questioning, elliptical utterance in turn 104 which appears to have had certain resonance in Ellen's inner processing. We could describe this exchange as an intermental continuation of processing or a momentary borrowing of consciousness aided by private speech. The following sections provide an overview of microgenesis as a process followed by an analysis of an essential aspect of microgenesis that I call microgenesis affordance. ${ }^{8}$

\section{Outlining microgenesis patterns}

This section outlines certain characteristics and patterns identified throughout the microgenesis instances as observed during the overt co-creation of knowledge in the collaborative language classroom. Activity, leading to microgenesis, that emerged throughout the data was characterised by the phases shown in Figure 1, although not all phases were present in all the microgenesis instances.

\section{Pre-microgenesis activity}

Pre-microgenesis activity normally entails organisational talk and an awareness/consciousness stage, ${ }^{9}$ leading to microgenesis affordance

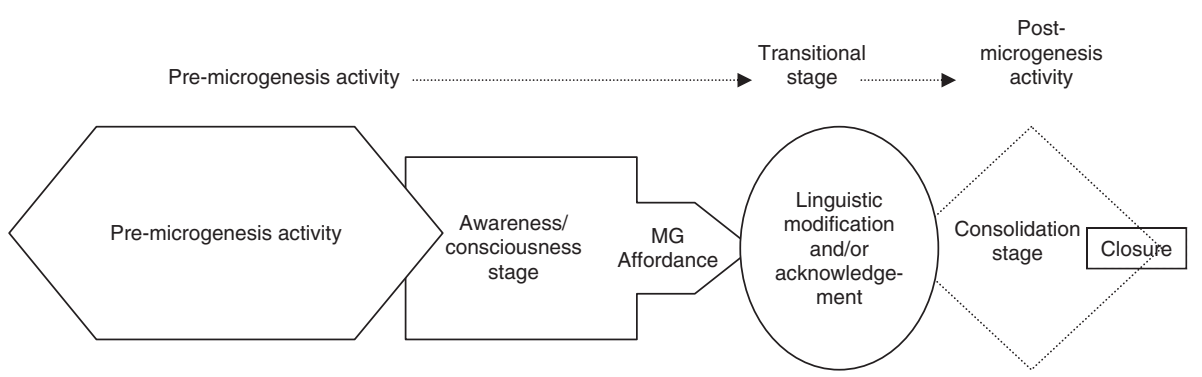

Figure 1: Microgenesis phases 
(see below). Organisational talk may refer to learners' speech that is directly related to task preparation, for instance when learners are discussing task instructions and/or how to tackle the task (metatalk). However, organisational talk is more often talk that mediates the co-creation of a common focus of attention so that the task can be initiated or continued without metatalk. In these cases, learners make use of reading aloud-either reading the instructions on the screen or their piece of paper, or reading the exercise they are focusing on, for example the sentence to be translated or to be completed.

Of crucial importance in this phase of collaborative activity is the moment of awareness, originated in the social plane, when learners realise that there is a discrepancy between their L2 and the target language (Schmidt and Frota 1986; Swain 2000). This moment can be directly related to the task the learners are completing, for instance when they are trying to fill in a gap in a sentence or recreating a text and they become aware of a lack of linguistic knowledge, or when that lack in knowledge is made apparent by their partner's language during collaboration, or their partner's correction. Alternatively, this awareness might be indirectly related to the task, for example while reading instructions, or while reading the text surrounding the linguistic focus intended by the task designer.

In this study of 22 instances of microgenesis identified in 12 protocols, 10 are related to target items and 12 are not (see Table 2). Two main-interrelatedissues arise from this fact, first of all, the relationship between task and activity $^{10}$ and secondly, the importance of consciousness/awareness in relation to the students' regulatory stage. Although the main linguistic foci targeted by the design are related to personal pronouns, infinitive verbs, radical changing verbs, and 'ser'l'estar', the data show how learners themselves determine what they focus on according to their own linguistic needs.

An important issue in the study of collaborative activity is to understand how it is that the social plane provides a platform for learners to capitalize on the consciousness/awareness stage and work further towards the modification of their L2 in order to achieve internalization. What are the microgenesis affordances upon which learners co-construct further knowledge to gain self-regulation? What the data show is that not only can collaborative activity provide a suitable platform for learners to focus on their L2, but it further supports cognitive engagement leading to modification of the learners' language and/or learning 'routines' (see the post-microgenesis stage below). Once learners' cognitive window gets activated, for example in the perception stage, learners working within their ZPD and with suitable interpsychological support can further benefit from the collaborative enterprise.

Although the awareness or consciousness stage and the microgenesis affordance are very closely linked within the process of microgenesis, they are not the same thing. Awareness precedes the microgenesis affordance; awareness precedes linguistic change. The affordance tools visible in the data 
Table 2: Linguistic focus in microgenesis instances

\begin{tabular}{llll} 
MG instance & Targeted? Y/N & Details & Location \\
\hline 1 & $\mathrm{~N}$ & Article (del) & CT1 \\
2 & $\mathrm{Y}$ & Personal pronoun (se) & CT1 \\
3 & $\mathrm{~N}$ & Vocabulary (éxito) & CT1 \\
4 & $\mathrm{Y}$ & Vocab (desarrollo intellectual) & PT1 \\
5 & $\mathrm{~N}$ & Vocab (aburrimiento) & PT1 \\
6 & $\mathrm{~N}$ & Vocab (esencial) & PT1 \\
7 & $\mathrm{Y}$ & Infinitive & CT2 \\
8 & $\mathrm{Y}$ & Radical changing verb & CT2 \\
9 & $\mathrm{Y}$ & Gerund & CT2 \\
10 & $\mathrm{Y}$ & Infinitive + pronoun & PT2 \\
11 & $\mathrm{~N}$ & Vocab (cuidado) & PT2 \\
12 & $\mathrm{Y}$ & Ser vs. estar & PT3 \\
13 & $\mathrm{~N}$ & Spelling (belleza) & PT3 \\
14 & $\mathrm{~N}$ & Morphology (trabajadores) & PT3 \\
15 & $\mathrm{~N}$ & Syntax (los) & PT3 \\
16 & $\mathrm{~N}$ & Syntax (tener) & PT3 \\
17 & $\mathrm{~N}$ & Vocab (historia natural) & PT3 \\
18 & $\mathrm{~N}$ & Morphology (sonrientes) & PT3 \\
19 & $\mathrm{Y}$ & Personal pronoun (se) & $2 \mathrm{PT} 1$ \\
20 & $\mathrm{Y}$ & Form of address & $2 \mathrm{PT} 1$ \\
21 & $\mathrm{Y}$ & Morphology (to know) & $2 \mathrm{CT} 2$ \\
22 & & Gerund & $2 \mathrm{CT} 2$ \\
\hline & & &
\end{tabular}

include private speech; explicit mediation by the expert either in the Ll or the target language (TL); co-constructed speech; the novice's spoken language, for example a desire to express him-/herself in the TL; and the novice's written language, for example having to spell a word or write a sentence.

\section{Transitional stage}

The transitional stage visible in microgenesis normally involves an overt acknowledgement of linguistic change, for example reflected through a discourse marker, and/or linguistic modification of the learner's L2. Analysis of the transitional stage in the instances of microgenesis helps us understand the regulatory state of the novice in relation to the developing item or structure. The data show three different patterns related to the vocal saliency 
of the transitional stage: (1) the transitional stage is overtly marked through a discourse marker such as 'oh'; (2) the transitional stage is acknowledged by means of an acknowledgment discourse marker such as 'umm' or 'yeah'; and (3) the stage is unmarked, the learner just incorporates the linguistic change.

Discourse markers are 'sequentially dependent elements which bracket units of talk' (Schiffrin 1987: 31). In the context of microgenesis, they bracket stages of cognitive development; they mark specific moments where L2 change is occurring or adjusting. As McLaughlin remarks, the presence of a discourse marker such as 'oh' is an overt indication of the 'sudden moments of insight' or 'clicks of comprehension' learners experience (McLaughlin 1987: 138). Therefore, discourse markers help us understand stages of regulation and relationship dynamics within the dyad. Moreover, they help us understand the processes of microgenesis in collaborative activity because they 'simultaneously' mark information backward and forward, they have both an 'anaphoric and cataphoric' quality and 'they are devices that work at discourse level' (Schiffrin 1987: 37). The latter is particularly relevant to differentiate between markers such as 'ah' and 'yeah' as being discourse markers that reflect new, and unexpected information, or 'ah' and 'yeah' functioning as acknowledgement markers that reflect new, but expected information, for instance. This kind of knowledge aids our analytic understanding of regulation and its relationship to microgenesis processes. The assessment of regulatory levels in the microgenesis instances studied was based on Aljaafreh and Lantolf's 'five general levels of transition from intermental to intramental functioning' (1994: 470):

Level 1 The learner is not able to notice, or correct the error, even with intervention.

Level 2 The learner is able to notice the error, but cannot correct it, even with intervention.

Level 3 The learner is able to notice and correct an error, but only under other-regulation. The learner understands assistance, and is able to react to the feedback offered.

Level 4 The learner notices and corrects an error with minimal, or no obvious feedback from the tutor and begins to assume full responsibility for error correction. However, development has not yet become fully intramental, since the learner often produces the target form incorrectly and may even reject feedback when it is unsolicited.

Level 5 The learner becomes more consistent in using the target structure correctly in all contexts. The individual is fully self-regulated.

Note: Levels 3 and 4, my bold.

Table 3 summarises the relationship between discourse markers and the level of regulation apparent in the subjects of microgenesis instances as found in the data. As Table 3 shows, there is no definitive link between the presence of a discourse marker and the level of internalization. In seven 
Table 3: Discourse markers and regulatory levels

\begin{tabular}{|c|c|c|c|c|}
\hline MG & Discourse marker & $\begin{array}{l}\text { Acknowledgment } \\
\text { marker }\end{array}$ & Unmarked & $\begin{array}{l}\text { Regulatory } \\
\text { stage }\end{array}$ \\
\hline CT1-MG3 & oh & $\begin{array}{l}\text { um (expected } \\
\text { information) }\end{array}$ & & 3 \\
\hline CTl-MGl & oh & & & 3 \\
\hline PT1-MG4 & ay yeah & & & 3 \\
\hline PT3-MG15 & $\mathrm{ah}$ & & & 4 \\
\hline 2PTl-MGI9 & ah & & & 4 \\
\hline 2CT2-MG2 l & entonces & & & 3 \\
\hline 2CT2-MG22 & ah...ppero & & & 4 \\
\hline PT3-MG13 & & $\begin{array}{l}\text { ah (expected } \\
\text { information) }\end{array}$ & & 3 \\
\hline PT1-MG5 & & ah ok & & 3 \\
\hline PT3-MG17 & & yeah & & 3 \\
\hline PT3-MG18 & & um & & 3 \\
\hline PT2-MG10 & & yeah um & & 4 \\
\hline PT2-MG1 l & & umm & & 3 \\
\hline CT1-MG2 & & & & 4 \\
\hline CT2-MG7 & & & & 4 \\
\hline CT2-MG8 & & & & 4 \\
\hline CT2-MG9 & & & & 4 \\
\hline PT3-MG14 & & & & 3 \\
\hline PT1-MG6 & & & & 4 \\
\hline PT3-MG16 & & & & 4 \\
\hline PT3-MG12 & & & & 3 \\
\hline 2PT1-MG20 & & & & 4 \\
\hline
\end{tabular}

microgenesis instances the transitional stage is marked by a discourse marker which highlights either a sense of unexpectedness brought about by the new information provided by the acting expert or the expression of self-realisation resulting from the interaction.

There are six instances marked by acknowledgement markers (as opposed to discourse markers) which are characterised by a higher degree of expectancy (assessed through the discourse surrounding the markers) when receiving the new information that affords linguistic change. The fact that in these cases learners appear to be expecting new information from their partner might be because (a) there was some pre-microgenesis activity preparing the learners for the new information; (b) the learner was immediately able to relate the new information to a known structure which 
somehow diminished the level of unexpectedness; and (c) in one case the learner was more regulated (level 4). Although the regulatory stage of these novices (level 3) still requires assistance from the expert, the level of revelation manifested when receiving the supportive/new information from their expert-partners is lower than in the MGIs where the discourse marker is the prevalent form.

Finally, the unmarked transitional stage shows a relationship with a higher degree of regulation (level 4) where 'the learner notices and corrects an error with minimal, or no obvious feedback' (see internalization levels above). Crucial to the absence of a marker in the transitional stage of these instances is pre-microgenesis activity and its characteristics. Expertise is co-created through collective scaffolding supporting the novice to take advantage of the environment affordance to obtain the needed knowledge, hence a higher level of regulation. There are, however, two examples of unmarked transitional stage and regulation level 3 in which the novice is scaffolded through drill pronunciation practice, or by means of co-constructed help.

\section{Post-microgenesis activity}

Post-microgenesis activity reflects the subtle consummation of applied knowledge. This is the linguistic space where the mastering of the tool becomes dually exercised; used for doing, as in task completion, and used for cognition, to consolidate language learning.

In most of the microgenesis instances, post-microgenesis activity simply bridges task completion, through the consummation of the communicative event. In other words, having controlled the language in question, learners are able to complete the exercise they are working on and move on towards the following activity phase. In some MGIs what could be described as discourse of schooling is exercised in a parallel plane in order to consolidate language internalisation. For instance, learners repeat the word or structure, normally while writing or typing the correct versions. However, some dyads go beyond repetition and engage in either personal or public learning routines: for example the novice makes use of $\mathrm{Ll}$, private speech, and cognitive statements such as 'I don't know', to contextualise the words they have been working on; learners engage in a dyadic effort where both novice and expert engage in a complementary drill practice and metalinguistic routine; or the novice applies his/her newly gained knowledge to exercise task completion and control through humour, for instance.

The analysis of microgenesis processes contributes to our understanding of the potential of dyadic collaborative activity in the language classroom. As we stressed above, studying microgenesis as a series of levels or stages facilitates our insight into learners' activity, but it does not mean that when learners are engaged in the co-construction of knowledge they necessarily follow those levels as separate procedures to achieve regulation. 


\section{Microgenesis affordance}

The following section is an analysis of a specific aspect of microgenesis that appears to be crucial for driving the learner's L2 forward, microgenesis affordance. Microgenesis affordance immediately precedes what we have identified as the transitional stage in microgenesis and it entails the processes and/or characteristics of the assistance provided by the more knowledgeable peer, for example the acting expert in that particular instance, or the characteristics of the linguistic environment that allow for a learner to capitalize on the affordance to modify and enhance his/her L2. The term affordance refers to 'a particular property of the environment that is relevant-for good or for ill-to an active, perceiving organism in that environment. An affordance affords further action (but does not cause or trigger it)' (van Lier 2000: 252). From the point of view of an ecological approach to language learning as the one advanced by van Lier, affordances are learning opportunities that can be used by an 'active and engaged' learner to take action over his/her language.

Microgenesis affordance is an essential characteristic of the MGIs observed in the data and it embodies the co-creation of common ground upon which opportunity for language learning is offered (e.g. through correction) and/or simply taken by the learners actively engaged in collaborative activity. Microgenesis affordances can be created by the two minds, so attuned to each other that they appear to be acting as an extension of one another, as we can see from the examples such as the ones involving private speech (see below), or they can be overtly created by means of assistance either requested or unrequested. Eleven out of twenty-two microgenesis instances identified in the data are characterised by the former type of co-constructed affordances (from now on referred to as affordances), and the other eleven are the result of overt assistance (from now on referred to as assistance); six requested instances vs. five unrequested.

\section{Assistance as microgenesis affordance}

In this section we will analyse the types of assistance encountered in the microgenesis instances and the mediational mechanisms that support the creation of assistance. We will do so by analysing representative instances of the type of assistance being studied.

\section{Requested assistance}

Three types of requested assistance were identified in the data, a straightforward reply, paraphrase followed by a reply, and co-constructed assistance. Replies were basically translations either from the target language (Spanish) into Ll (English) or vice versa; the paraphrase was followed by a reply in the Ll; and the co-construction followed an implicit request in the Ll. What determines the kind of assistance the expert provides, however, 
depends on factors that ultimately impact on the learning experience the dyad/group as a whole is undergoing. The most important of those factors is the sensitivity shown by the expert towards (a) the partner requirements as manifested while struggling with a particular word, for example; (b) the task goals; and (c) the acting expert's personal objectives (for instance providing the requested assistance efficiently and not to become distracted from the task goal). The result is a dialogic opportunity for both learners that arises from an asymmetric situation. We will illustrate the above assertions through a contrastive analysis of microgenesis instances and the choice of help provided by the learners taking part in those exchanges.

\section{L1 Reply}

Use of Ll can prove to be a very effective mediational mechanism if investigated within its situated context (see Swain and Lapkin 1982, 2000; Antón and DiCamilla 1998; de Guerrero and Villamil 2000). Two of the instances that involve use of Ll in the provision of help exemplify how the experts' choices are affected by what is going on in the collaborative act. The first instance (MG13) illustrates Mina's ability to provide the requested assistance by Ellen in an effective, economical way that did not disrupt the overall focus of task implementation, for example the completion of an interview reconstruction.

\section{(CT1) MGI3}

148 E 'en los' (.) 'en cuanto a' ((reading quietly)) que ah (.) talking of technology

'in the' (.) 'in relation to' that ah (.) talking of technology

149 M umm ah

150 E 'qué tan importante' es 'el'

'how important' is 'the'

151 M si (.) es el (.) es el

yes is the is the

$152 \mathrm{E} \quad$ es el (.) es el éxito? o (.) no?

is the is success? or (.) no?

$153 \mathrm{M}$ no en tec tecnología?

no in tec technology?

$\Longrightarrow 154$ E no se no se qué sign significa su 'éxito en el poder el dinero' (.) éxito es

I don't know what success means in 'power money' success is

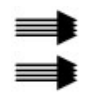

$155 \mathrm{M}$ success

156 E oh

157 M 'poder' (.) um 'qué tan importante' (.) how important 'es el es el el' 'power' (.) um 'how important' (.) how important is the is the the' 


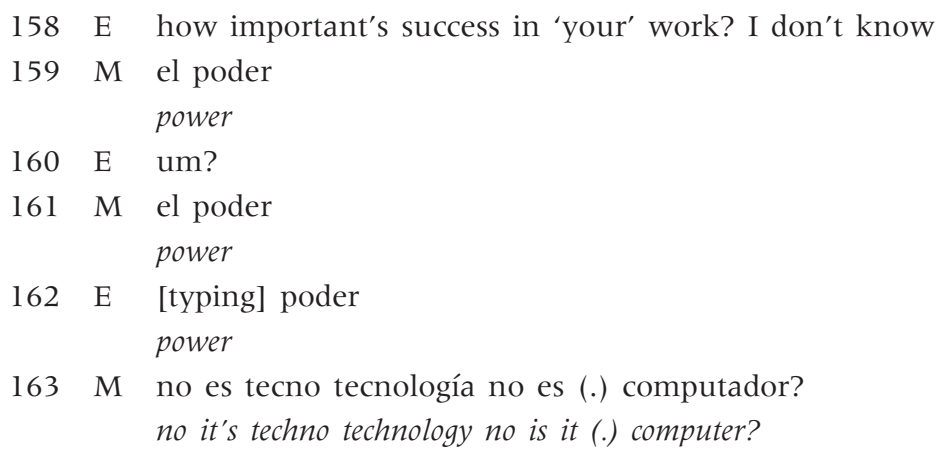

The fact that Mina simply replies in the Ll (t155) facilitates the provision of help without losing focus on the task goal, for example filling in a particular gap. Mina's behaviour reflects a recognition of both, her partner's specific need-Ellen has been actively trying to learn the meaning of 'éxito' - but also her own. She has been using repetition as a regulatory tool to gain control over the task and would not want to lose that focus by engaging in a more lengthy process that could potentially distract her from the immediate goal. Therefore, paraphrasing or exemplification, for instance was not Mina's choice. In this situation, use of the Ll was an effective tool for the collaborative enterprise as a whole. We can compare this instance with a second MGI where Ll is also used as a mediational tool for the provision of requested assistance, but whose characteristics are different.

\section{Paraphrase and Ll reply}

(PT1) MGI4

$12 \mathrm{~L}$ um qué es desarrollo intelectual?

um what's intellectual development?

$13 \mathrm{H}$ es umm es como (.) ah (.) que es umm que tu aprende ah durante ah su carrera $=$

it's umm it's like (.) ah (.) that it's umm that you learn ah during your career $=$

$14 \mathrm{~L}=\mathrm{ok}$

$15 \mathrm{H}$ intellectual development

16 L ay yeah ((laughter))

$17 \mathrm{H}$ ah

18 L no ((laughter)) no ()

Although in this instance the expert also uses Ll to provide assistance to the novice, the $\mathrm{Ll}$ is not the immediate option chosen by Hena. After being asked, in the target language, what the meaning of intellectual development is (t12), Hena resorts to paraphrasing. It has to be noted that, unlike 'éxito' in 
MG13, 'desarrollo intelectual' is a working item for the completion of the task, as the learners are trying to hierarchically organise a series of concepts, including intellectual development, according to their own priorities. Understanding the terms in this part of the task would therefore have been perceived as important by both learners. Hena's efforts to explain the meaning of the item in Spanish suggests that she is actively taking this classroom exercise as a learning activity. She is behaving as a language student who is constantly reminded of the importance of using the TL as much as possible, but as importantly, she seems to be taking advantage of this affordance, initiated by her partner, to stretch her L2 (notice the fillers, repetition, and pauses in turn 13). In turn 15, however, she provides the translation of the term into English after the acknowledgement marker 'ok' quietly uttered by Liam in turn 14. Although 'ok' would normally mean understanding of the interlocutor's message, we-as analysts-learn through turns 16-18 what Hena-as a committed collaborator and acting expertimmediately perceived in turn 14: that Liam had not really grasped the meaning of 'desarrollo intelectual' from Hena's paraphrase. The fact that Hena uses Ll as a further tool to convey the meaning of the words and provide the required assistance to her classmate suggests that even though she was cognitively engaged in her Spanish performance, she was also sensitively open to and aware of her classmate's needs.

This MGI is a clear example of how learners acting as experts in a particular situation are able to provide scaffolded help and how an active learner takes advantage of the collaborative situation to engage in a process of learning (stretching her own L2) and teaching (providing the required help) simultaneously. Finally, we also witness the internalization process undergone by Liam who progresses from object-regulated behaviour (verbally pointing at the unknown term), through other-regulated (Hena's assistance), to self-regulation (a linguistic understanding that allowed him to even use humour in turn 18 in relation to the term). Of course, he had access to the term in the Ll and we do not pretend to claim he would be in a position to use the Spanish expression in other contexts and situations in the long term, but what is evident is that the collaborative situation in which the expert provided graded help was an effective context that allowed for both learners to actively engage in a learning process (Aljaafreh and Lantolf 1994; Donato 1994).

\section{Co-construction}

The third type of requested assistance observed during microgenesis is co-construction. According to Ohta, co-construction is an explicit form of assistance 'as the peer chimes in with a syllable, inflection, word, or phrase, or completes an utterance started by the peer. Co-construction sometimes results in vertical construction, in which peers collaborate to produce 
an utterance, alternately providing words or phrases to the growing utterance' (Ohta 2001: 88-9). The example of requested assistance in our microgenesis data set results indeed in a vertical construction.

(PT3) MGI17

\begin{tabular}{|c|c|c|}
\hline 296 & A & [the history museum (.) \\
\hline 297 & $\mathrm{~J}$ & eh ah la galeria tate (.) \\
\hline & & eh ah gallery tate \\
\hline 298 & $\mathrm{P}$ & $\begin{array}{l}\text { eh um el museo du eh natural de historia, } \\
\text { eh um the museum of eh natural history }\end{array}$ \\
\hline 299 & $\mathrm{~J}$ & de histo de (.) de \\
\hline 300 & $\mathrm{P}$ & historia \\
\hline 301 & $\mathrm{~J}$ & his to ria \\
\hline 302 & A & [natural \\
\hline 303 & $\mathrm{P}$ & [historia \\
\hline 304 & A & yeah de historia natural \\
\hline 305 & $\mathrm{~J}$ & that's it (.) y eh \\
\hline
\end{tabular}

This instance is part of an ongoing process of co-construction where the learners (a triad) are creating a text about London which follows the reconstruction of a text about Mexico City. Students are listing places of attraction in London one of them being 'the history museum' (t296) proposed by Alex in English. The expression of the place in English is rightly interpreted by Jack and Paul as a request for assistance and the three of them subsequently engage in the co-construction of the expression in Spanish. This is another example of the use of English as an economical resource that far from compromising the collaborative activity becomes a facilitator for it. The three learners engage in collective scaffolding and achieve together what was beyond individual achievement (see Donato 1994). This group performance, moreover, transcends the dyadic interaction and what was originally a collective effort to help Alex, becomes a beneficial experience for the three learners at different levels. While they are all working to co-construct 'museo de historia natural', Jack and Paul are also dealing with another issue in turns 299-301 where Jack is having problems with the word 'historia' and Paul produces the whole word for him (t300).

The three examples of requested help analysed in this section provide an insight into the ways learners respond to each other's needs during collaboration as well as how a request for help turns into an affordance for the group. These are clear benefits of the dialogic experience where linguistic actions exceed the individual by having an impact on both participants of an exchange. 


\section{Unrequested assistance: corrective feedback}

There were five instances of unrequested assistance out of 22 instances of microgenesis. The five cases each involved a recast, which has been defined by Ohta as 'an utterance that reformulates a learner's erroneous utterance. Recasts may contrast with learner utterances phonologically, morphologically, syntactically, or semantically, but are based on the learner's erroneous utterance and maintain semantic contiguity with it. Recasts are immediately subsequent to the utterance' (Ohta 2001: 141). Two of the instances were phonological corrections that were followed by pronunciation practice whereas three were recasts of a morphological nature, for example:

(PT3) MGI15
$131 \mathrm{j}=$ las las mexicanos
$={ }^{*}$ the ${ }^{*}$ the mexicans ((wrong gender for the needed article))
132 a los mexicanos [son morenos
the mexicans are dark-skinned
$133 \mathrm{j} \quad$ [ah los mexicanos
ah the mexicans

\section{Other types of microgenesis affordances}

I will now refer to microgenesis instances where participants co-create learning affordances which are not based on corrective feedback. I identified eleven such instances in the data. These instances entail characteristics of the linguistic environment that allow for a learner to capitalize on the affordance and thus enable him/her to modify and enhance their L2. I will illustrate this point by means of two examples.

\section{Interwoven consciousness}

This first example of microgenesis affordance both helps us understand some of the ways in which learners tackle linguistic problem solving by making language more manageable, but also how learners benefit from each other's mental activity.

(CT2): MGI8

114 Henry 'Elisa no es la chica que habla alemán' (.) que pasó? (.) ok (Hn) 'avanzar' 'she had to practise but carried on reading' umm,

'Elisa isn't the girl that speaks German' (.) what happened? (.) ok 'go on'

'she had to practise but carried on reading' umm, 


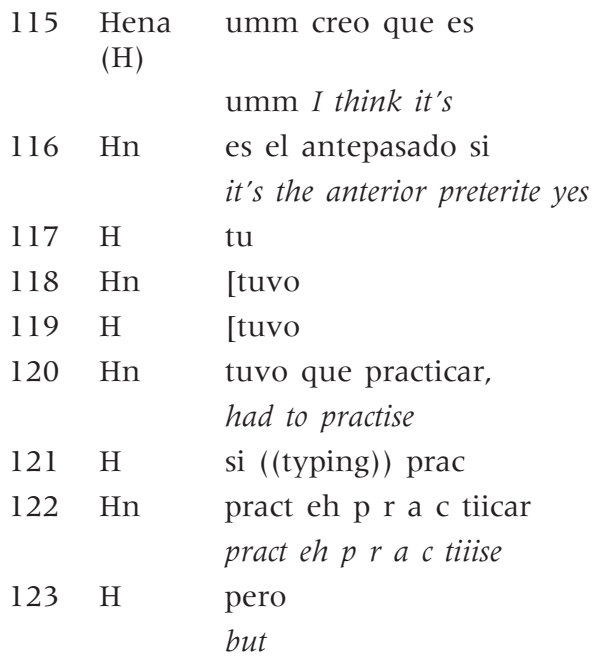

$124 \mathrm{Hn} \quad$ carried se seguir? seg she carried on reading pero (.) no se carried on continuar?

carried ca carry? car she carried on reading but (.) I don't know carried on to continue?

$125 \mathrm{H} \quad$ si cont

yes cont

126 Hn continuó? no se como se dice el pasado continue? ((mumbles and she writes))

carried on? I don't know how to say the past carried on? ((incorrect tacit subject))

$127 \mathrm{H} \quad$ con ((typing, they smile)) [pero

con ((typing)) [but

$128 \mathrm{Hn} \quad$ [pero es es el material ((they smile))

[but it's the material

$129 \mathrm{H}$ pero continuo (.) es el=

but carried on (.) it's the $=$

$130 \mathrm{Hn}=$ no s no estoy seguro (.) continuo=

$=I^{\prime} m$ no I'm not sure (.) carried on

$131 \mathrm{H} \quad=$ [gerundio

$=[$ gerund

$132 \mathrm{Hn} \quad$ [a leer?

[to read?

$133 \mathrm{H}$ después de [continuar

after to [continue

$134 \mathrm{Hn} \quad$ [continuar leyendo leer leyendo (.) leyendo?= [to continue reading to read reading (.) reading?

$135 \mathrm{H} \quad=$ si es leyendo porque es el gerun gerundio average(.) después de seguir y continuar 
yes it's reading because it's the gerund average gerund (.) after to carry on and to continue

$136 \mathrm{Hn} \quad($ (he types)) l e y e $\mathrm{n} \mathrm{d}$ o punto

re a d ing full stop

As we can see from the beginning of the instance learners are collaboratively tackling the translation into Spanish of the sentence she had to practise but carried on reading'. In turn 124 Henry isolates the problematic verb 'to carry on' which can be translated both as 'seguir' or 'continuar'. It is relevant to note the various processing strategies that help the learners achieve regulation as they are revealed in that turn and which are common in collaborative activity. First of all, Henry isolates the problematic item 'carried', then we witness a memory retrieval process in two stages, first for a syllable, then the whole word: 'se seguir?' followed by just 'seg' having realised the discrepancy between 'carried' (past tense) and 'seguir' (correct verb, but in the infinitive form). He uses repetition and codeswitching to continue his efforts when he repeats 'she carried on reading' as a tool to try and gain control but switches into Spanish for the conjunction 'pero' which they already control. After a brief pause followed by his cognitive statement 'no $\mathrm{se}^{\text {', }}$ he tries to regulate again through repetition of 'carried on' and produces 'continuar?', a synonym of 'seguir' still in infinitive.

In turn 125 Hena intervenes to accept 'continuar' although she stops short at 'cont' presumably because she is also having problems with the past tense. Nevertheless, her intervention makes them both choose 'continuar' which enables them to focus on this and resume their efforts. Turn 126 is a hypothesis testing turn for Henry who tries both forms of the past tense 'continuó' and 'continué', some metalanguage and probably some private speech (which is indecipherable because he is mumbling). After some comments related perhaps to typing problems, Hena rebuilds on Henry's suggestions and types-while repeating-'pero continuó', which is correct, in turn 129.

Finally, she starts her construction of a grammar rule that eventually helps them achieve regulation. Turns 129 to 135 are the product of interwoven consciousness between these two learners which culminates with Henry's internalization processes-rooted in Hena's metalanguage-and his own production of the correct form 'leyendo' (followed by a little learning routine in turn 134). So through turns 129, 131, 133, and 135 Hena retrieves the grammar rule, 'it is the gerund, after to continue because it is the average gerund after to carry on and to continue', and by doing so she enables Henry to move from the incorrect form 'a leer' to the correct 'leyendo' through the even turns 130, 132, and 134. In this particular instance the fact that both learners approach the task differently is to their advantage. While Hena focuses on retrieving a grammar rule, Henry focuses instead on trying out the verb forms. 


\section{Mapping knowledge}

Another way in which learners take advantage of the collaborative act to engage in L2 processing is by questioning their partner's utterance and mapping it against their own knowledge. The following instance involves the co-translation of the sentence 'her boyfriend doesn't know how to play the piano.'

\section{(CT2) MGI7}

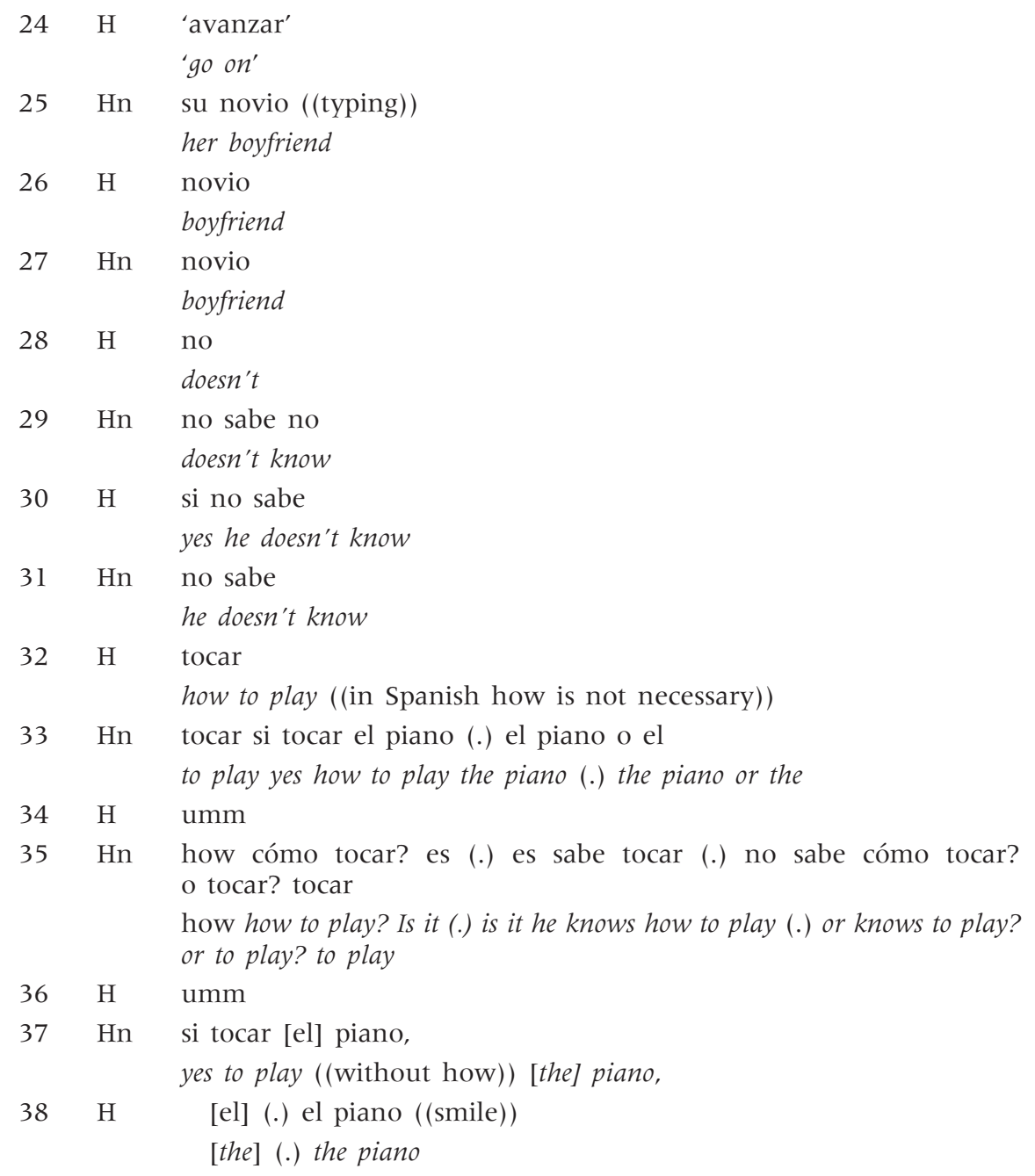

From turn 24 to 32 Hena and Henry proceed with the task of translating the sentence by means of co-construction, they co-build language by repeating what their partner said and building on it to develop the structure 
in hand. However, in turn 33 there is a change in Henry's performance. At first, he accepts Hena's suggestion 'tocar' as a translation for 'how to play' which is the correct form in Spanish, since the 'how' becomes redundant, but then he becomes engaged in dialogic thought about the structure, for example a pause followed by the repetition of 'el piano' and the introduction of the disjunctive conjuction ' $\mathrm{O}$ ' (or) which suggests he is thinking about a different option. The second part of this turn indicates what becomes apparent later on, that Henry is questioning the need for 'como' (how) before the verb 'tocar' (to play). Hena's backchannel cue 'umm' in turn 34 encourages him to bring forward his language questioning by making his thought explicit in turn 35 where he reveals he is contrasting the target language structure against his $\mathrm{Ll}$.

This process of 'matching up' or 'mapping' one structure over another is occurring through and, importantly, because of the regulatory mechanisms brought about by the intermental activity in which these two learners are engaged. Henry starts turn 35 being very much object-regulated, having to linguistically 'point at' the trouble source and contrast it in both languages, 'how cómo tocar? is it he knows to play or knows how to play?' and then goes on, at the end of the turn, being aided by the verbalization sound of 'or to play? to play' to finally achieve regulation in turn 37 while uttering the whole correct verb phrase 'sí tocar el piano' (yes to play the piano). Although in these last stages of the instance Hena just intervenes twice with backchannel cues (turns 34 and 36), her assistance in the internalisation process, incidental as it might be, is important. First of all, she produces the correct structure which affords Henry's engagement with, and questioning of, the form. Secondly, Henry's efforts to communicate to Hena his questioning of whether they should include 'como' (how) as part of the translation are, at the same time, facilitating his language internalisation.

\section{CONCLUSION}

Sociocultural theory postulates that knowledge is created interpsychologically, not conceived as a pre-existing product to be exchanged, and that the co-construction of knowledge is always mediated by either physical or psychological tools. Learning is a situated activity 'therefore it unfolds in different ways under different circumstances' (Donato 2000). Throughout this paper we witnessed the mediated co-construction of knowledge by the participants. The learners made use of semiotic mechanisms to different degrees and for different purposes, thus reflecting their tasks perceptions and their particular goals and needs.

In this paper, I highlighted the importance of microgenesis as both tool and focus of study. The object of this investigation was to identify and study those instances where language learning was taking place during interaction, while-simultaneously_gaining a deeper understanding of how the process 
was taking place. Ohta remarks, when referring to obtaining and providing assistance, that the interactional mechanisms involved...during language learning tasks have been little examined' (Ohta 2000: 52). This study aimed to contribute to the body of research into how the learners deploy some specific semiotic resources such as use of $\mathrm{Ll}$, repetition, and reading aloud to gain control over the task in hand, and to facilitate knowledge co-construction and L2 development (Frawley 1992; DiCamilla and Anton 1997; Roebuck 2000; Swain and Lapkin 2000).

In addition, the potential interface between speech and cognitive activity was illustrated by means of our insights into the discourse marker. Discourse markers were found to bracket stages of cognitive development; more specifically, they appear to mark moments where L2 change is occurring or adjusting. Therefore, their microgenetic study can help us understand stages of regulation and relationship dynamics within the dyad. In other words, examining the collaborative enterprise through the microgenetic lens provided the analytic tool for the simultaneous study of individual semiotic tools and the process of language development without creating a vacuum between dialogue and activity.

A crucial issue that has been eluding Sociocultural SLL researchers remains inconclusive: is it possible to claim that the L2 change observable during interaction does become internalised? (For exceptions, see developmental studies over long periods, e.g. Ohta 2001; Belz and Kinginger 2003; Belz and Vyatkina 2005). It was not within the scope of this study to provide such evidence, but I believe it is important for future research from this theoretical stance to accurately establish the long-term effect that microgenesis (i.e. 'a local, contextualized learning process', Mitchell and Myles 2004: 198) has on the learners' L2. However, it is encouraging, from a Sociocultural approach, to be able to witness a process that might have contributed to the students' progression from other to self-regulation.

Final version received May 2007

\section{ACKNOWLEDGEMENTS}

My gratitude goes to the students who allowed me to record their interactions and who took part in the study. I would like to thank Florence Myles, Nigel Harwood, and the anonymous reviewers for their insightful comments. Any errors remain solely my own.

\section{APPENDIX: TRANSCRIPTION CONVENTIONS}

$$
\begin{aligned}
\text { italics } & =\text { translation into English } \\
'-' & =\text { reading aloud } \\
(.) & =\text { pause } \\
() & =\text { indecipherable } \\
(()) & =\text { comments } \\
\# & =\text { turn number }
\end{aligned}
$$


$=$ latching

[ = overlapping

? = rising intonation

$\rightarrow \quad=$ turn to be discussed in the text

$\mathrm{S}=$ speaker (pseudonym initial)

$\mathrm{CTl}=$ protocol 1 computer-based task $\mathrm{l}$

$2 \mathrm{PTl}=$ protocol 2 paper-based task 1 , etc.

\section{NOTES}

1 Although the kind of analysis pursued in this investigation shares characteristics with other types of linguistic analysis, for example with Conversation Analysis, it differs from them in that 'cognition and the social and cultural context of talk are considered legitimate concerns....Dialogue is treated as a form of intellectual activity-as a mode of thinking [and the analysis] is concerned not only with the processes of joint cognitive engagement, but also with their developmental and learning outcomes' (Mercer 2004: 141).

2 For an in-depth discussion of conceptualisations of this term, see Wells (1999: 51-97).

3 The activity in which the individual is engaged in meaning making with others in an attempt to extend and transform their collective understanding with respect to some aspect of a jointly undertaken activity' (Wells 1999: 84).

4 There were other, supplementary, instruments for data collection in the study (pre/post language tests, and two different types of questionnaires). For information about the full study see Gánem-Gutiérrez, 2004.

5 Package for qualitative data analysis from QSR.

6 The CALL tasks were created with two pieces of software, a Web page generator, GoLive by Adobe, and the authoring programme, Hot Potatoes by Half-Baked.
7 Private speech is self-directed language that can be observed when learners are experiencing cognitive challenges and it is employed to gain self-regulation and control task performance (Donato 1994, 2000; McCafferty 1994). The identification and subsequent analysis of private speech utterances presents, however, difficulties and even controversies (cf. Wells 1998: 349-50), not least because of the practicalities of 'capturing' it during data collection. Private speech is often uttered in a low voice, and includes elliptical language, as was the case for the utterance in question.

8 'The word Affordance was coined by the psychologist James Gibson to refer to a reciprocal relationship between an organism and a particular feature of its environment (1979)' (van Lier 2000: 252).

9 I am using the term consciousness in the Vygotskian sense, meaning human 'awareness of and control over our mental abilities' (Lantolf and Thorne 2006: 60; see also Wertsch 1985: 27 and Roebuck 2000: 81).

10 I refer to task as a focused piece of work that serves as a blueprint for learners to engage in meaningful activity in pursuit of a goal. The activity generated by the learners' interaction with the task is a unique event since it is defined by the processes that develop as a result of that interaction in combination with the learners' own goals and perceptions of the task (cf. Coughlan and Duff 1994: 175). 


\section{REFERENCES}

Aljaafreh, A. and J. P. Lantolf. 1994. 'Negative feedback as regulation and second language learning in the zone of proximal development,' Modern Language Journal 78: 465-83.

Anton, M. and F. DiCamilla. 1998. 'Sociocognitive functions of $\mathrm{Ll}$ collaborative interaction in the L2 classroom,' The Canadian Modern Language Review 54: 314-42.

Arnail, S., M. Holmes, and H. Street. Hot Potatoes. Half-Baked Software.

Belz, J. A. and C. Kinginger. 2003. 'Discourse options and the development of pragmatic competence by classroom learners of German: The case of address forms,' Language Learning 53: 591-647.

Belz, J. A. and N. Vyatkina. 2005. 'Learner corpus analysis and development of L2 pragmatic competence in networked intercultural language study: The case of German modal particles,' The Canadian Modern Language Review 62/1: 17-48.

Coughlan, P. and P. A. Duff. 1994. 'Same task, different activities: Analysis of SLA task from and activity theory perspective' in P. Lantolf and G. Appel (eds): Vygotskian Approaches to Second Language Research. Norwood, NJ: Ablex.

De Guerrero, M. C. M. and O. S. Villamil. 2000. 'Activating the ZPD: Mutual scaffolding in L2 peer revisions,' Modern Language Journal 84: 51-68.

DiCamilla, F. J. and M. Anton. 1997. 'Repetition in the collaborative discourse of L2 learners: A Vygotskian perspective,' The Canadian Modern Language Review 53: 609-33.

Donato, R. 1988. Beyond group: A Psycholinguistic rationale for collectivity in second language learning. Unpublished Doctoral Dissertation, University of Delaware.

Donato, R. 1994. 'Collective scaffolding in second language learning' in P. Lantolf and G. Appel (eds): Vygotskian Approaches to Second Language Research. Norwood, NJ: Ablex.

Donato, R. 2000. 'Sociocultural contributions to understanding the foreign and second language classroom,' in J. P. Lantolf (ed.): Sociocultural Theory and Second Language Learning. Oxford: Oxford University Press.

Frawley, W. 1992. Linguistic Semantics. Hillsdale, NJ: Lawrence Erlbaum Associates.
Gánem-Gutiérrez, A. 2003. 'Beyond interaction: The study of collaborative activity in computermediated tasks,' ReCALL 15/1: 94-112.

Gánem-Gutiérrez, A. 2004. The Processes of Collaborative Activity in Computer-Mediated Tasks: in Search of Microgenesis. Unpublished doctoral dissertation. University of Southampton.

Hoven, D. 1999. 'CALL-ing the learner into focus: Towards a learner-centred model,' in R. Debski and M. Levy (eds): WorldCALL: Global Perspectives on Computer-assisted Language Learning. Lisse: Swets \& Zeitlinger.

Kinginger, C. and J. A. Belz. 2005. 'Socio-cultural perspectives on pragmatic development in foreign zlanguage learning: Microgenetic case studies from telecollaboration and residence abroad,' Intercultural Pragmatics 2/4: 369-421.

Kowal, M. and M. Swain. 1997. 'From semantic to syntactic processing. How can we promote it in the immersion classroom?' in R. K. Johnson and M. Swain (eds): Immersion Education: International Perspectives. Cambridge: Cambridge University Press.

Lantolf, J. P. (ed.) 2000. Sociocultural Theory and Second Language Learning. Oxford: Oxford University Press.

Lantolf, J. P. and G. Appel. (eds) 1994. Vygotskian Approaches to Second Language Research. Norwood, NJ: Ablex.

Lantolf, J. P. and S. L. Thorne. 2006. Sociocultural Theory and the Genesis of Second Language Development. Oxford: Oxford University Press.

Leontiev, A. N. 1978. Activity, Consciousness and Personality. Englewood Cliffs, NJ: Prentice Hall.

McCafferty, S. G. 1994. 'The use of private speech by adult ESL learners at different levels of proficiency' in J. P. Lantolf and G. Appel (eds): Vygotskian Approaches to Second Language Research. New Jersey: Ablex Publishing Corporation.

McLaughlin, B. 1987. Theories of Second-language Acquisition. London: Edward Arnold.

Mercer, N. 2004. 'Sociocultural discourse analysis: Analysing classroom talk as a social mode of thinking,' Journal of Applied Linguistics 1/2: 137-68.

Mercer, N. and P. Scrimshaw. 1993. 'Researching the electronic classroom' in P. Scrimshaw (ed.): Language, Classrooms e Computers. London: Routledge.

Mitchell, R. and F. Myles. 2004. Second Language Learning Theories, 2nd edn. London: Arnold. 
Ohta, A. S. 1995. 'Applying sociocultural theory to an analysis of learner discourse: Learner-learner collaborative interaction in the zone of proximal development,' Issues in Applied Linguistics 6: 93-121.

Ohta, A. S. 2000. 'Rethinking interaction in SLA: Developmentally appropriate assistance in the zone of proximal development and the acquisition of L2 grammar' in J. P. Lantolf (ed.): Sociocultural Theory and Second Language Learning. Oxford: Oxford University Press.

Ohta, A. S. 2001. Second Language Acquisition Processes in the Classroom: Learning Japanese. Mahwah, NJ: Lawrence Erlbaum.

Psathas, G. 1995. Conversation Analysis: The Study of Talk-in-interaction. Thousand Oaks: Sage.

Robbins, D. 2001. Vygotsky's Psychology-Philosophy: A Metaphor for Language Theory and Learning. New York: Kluwer Academic.

Roebuck, R. 2000. 'Subjects speak out: How learners position themselves in a psycholinguistic task' in J. P. Lantolf (ed.): Sociocultural Theory and Second Language Learning. Oxford: Oxford University Press.

Roschelle, J. and S. D. Teasley. 1995. 'The construction of shared knowledge in collaborative problem solving' in C. O'Malley (ed.): Computer Supported Collaborative Learning. Berlin: Springer-Verlag.

Schiffrin, D. 1987. Discourse Markers. Cambridge: Cambridge University Press.

Schmidt, R. W. and S. N. Frota. 1986. 'Developing basic conversational ability in a second language: A case study of an adult learner of Portuguese' in R. R. Day (ed.): Talking to Learn: Conversation in Second Language Acquisition. Rowley: Newbury House.

Sfard, A. 1998. 'On two metaphors for learning and the dangers of choosing just one,' Educational Researcher 27: 4-13.

Swain, M. 1995. 'Three functions of output in second language learning' in G. Cook and B. Seidlhofer (eds): Principle and Practice in Applied Linguistics. Oxford: Oxford University Press.

Swain, M. 1997. 'Collaborative dialogue: Its contribution to second language learning,' Revista Canaria de Estudios Ingleses 34: 115-32.

Swain, M. 1998. 'Focus on form through conscious reflection' in C. Doughty and J. Williams (eds): Focus on Form in Classroom Second Language Acquisition. Cambridge: Cambridge University Press.
Swain, M. 2000. 'The output hypothesis and beyond' in J. P. Lantolf (ed.): Sociocultural Theory and Second Language Learning. Oxford: Oxford University Press.

Swain, M. and S. Lapkin. 1995. 'Problems in output and the cognitive processes they generate: A step towards second language learning,' Applied Linguistics 16/3: 371-91.

Swain, M. and S. Lapkin. 1998. 'Interaction and second language learning: Two adolescent French immersion students working together,' The Modern Language Journal 82: 320-37.

Swain, M. and S. Lapkin. 2000. 'Task-based second language learning: The uses of the first language,' Language Teaching Research 43: 251-74.

Swain, M. and S. Lapkin. 2001. 'Focus on form through collaborative dialogue: Exploring task effects' in M. Bygate, P. Skehan and M. Swain (eds): Researching Pedagogic Tasks: Second Language Learning, Teaching and Testing. London: Longman, pp. 99-118.

Van Lier, L. 2000. 'From input to affordance: Social-interactive learning from an ecological perspective' in J. P. Lantolf (ed.): Sociocultural Theory and Second Language Learning. Oxford: Oxford University Press.

Vygotsky, L. S. 1978. Mind in Society. Cambridge, MA: Harvard University Press.

Vygotsky, L. S. 1986. Thought and Language. Cambridge, MA: MIT Press.

Wells. G. 1992. 'The centrality of talk in education' in K. Norman (ed.): Thinking Voices: The Work of the National Oracy Project. London: Hodder \& Stoughton.

Wells, G. 1998. ‘Using L1 to Master L2: A response to Anton and DiCamilla's "Socio-cognitive functions of Ll collaborative interaction in the L2 classroom", ' Canadian Modern Language Review 54: 343-53.

Wells, G. 1999. Dialogic Inquiry: Toward a Sociological Practice and Theory of Education. Cambridge: Cambridge University Press.

Wertsch, J. V. (ed.) 1981. The Concept of Activity in Soviet Psychology. Armonk, NY: M. E. Sharpe.

Wertsch, J. V. 1985. Vygotsky and the Social Formation of Mind. Cambridge, MA: Harvard University Press.

Wertsch, J. V. 1991. Voices of the Mind: A Sociocultural Approach to Mediated Action. London: Harvester. 